\title{
直交座標型非ホロノミックロボットの製作と制御実験
}

\author{
町 田 健 一*1 羅 正 華*2 船 木 陸 議*2
}

\section{Prototyping and Control Experiments of a Cartesian Nonholonomic Robot}

\author{
Kenichi Machida*1, Zheng-Hua Luo*2 and Michitaka Funaki*2
}

\begin{abstract}
In a previous paper, the present authors proposed to constructing a Cartesian nonholonomic robot using two balls and two actuators. In order to find whether the robot would be physically realizable and whether good control results could be expected, a prototype is constructed and control experiments are conducted. A new sensor which can detect the position and orientation of the robot is also developed, using two mouses used in computers. Both simulations and control experiments are performed, yielding very similar and acceptable control results, showing the correctness of the kinematic model, the efficacy of the control algorithms, and the physical realizability of the proposed nonholonomic robots.
\end{abstract}

Key Words: Nonholonomic Systems, Cartesian Robots, Chained Form, Stabilization, Experiment

\section{1.はじめに}

ホロノミック, 非ホロノミックとは力学的拘束を分類する用 語であり, 非ホロノミックシステムとは積分不可能な拘束を受 けるシステムのことをいう. 身近なところでは自動車が非ホロ ノミックな拘束を受けるシステムであり，このために自動車は ステアリングとアクセルという二つの入力で位置 $(x, y)$ と姿 勢 $\phi$ という三つの状態を制御できる．しかし，はじめに回転中 心を移動させなければ任意な方向に速度を発生することができ ないため制御は難しく，綐列駐車や車庫入れといった動作には ドライバの巧みな運転技術が要求される.

一方，ホロノミック特性を有するロボットは，平面上の任意 の位置・姿勢で移動速度がゼロでない状態から平行移動およ び回転という独立した平面運動が可能であるため任意の位置・ 姿勢への制御が簡単である。こうしたホロノミック特性を有す る全方向移動ロボットの機構に関しては, 三つの球を使ったも の [2][3] 4 個のボールと 4 本のロッドで構成される 2 組のト ラックを使ったもの [4] などが研究されている.いずれもその ホロノミック特性を実現するためにアクチュエータの数は状態 量の数と同じかそれ以上用いる必要がある。

文献 [1]では，より少ないアクチュエータでより多くの自由度 を実現することを目指し，二つの球をそれぞれに取り付けられ

\footnotetext{
原稿受付 1995 年 12 月 17 日

${ }^{* 1}$ 長岡技術科学大学大学院工学研究科

$* 2$ 長岡技術科学大学

${ }^{* 1}$ Graduate School of Engineering, Nagaoka University of Technology

${ }^{* 2}$ Nagaoka University of Technology
}

たアクチュエータで独立に駆動することで平面内の位置 $(x, y)$ と姿勢 $\phi$ の 3 自由度を制御できる直交座標型非ホロノミックロ ボットの原理を提案し，フィードバック制御のシミュレーショ ン結果を示したが，このようなロボットは果たして実現できる かどうか, また良好な制御実験結果が得られるかなどの疑問が 残された。

本論文では，上記非ホロノミックロボットを製作し，制御実 験を行ったので結果を報告する．以下，本ロボットの機構を説 明した後, 運動学モデルを示す.また, マウスを利用して位置・ 姿勢センサを開発したので, その原理とセンサの性能評価に ついて述べる. 最後にフィードバック制御実験結果を計算機シ ミュレーション結果と比較しながら検証する。

\section{2. 直交座標型非ホロノミックロボット}

\section{1 ロボットの製作}

文献 [1] で設計した直交座標型非ホロノミックロボットを製 作した．製作したロボットの外観を Fig. 1 に，組み立て図を Fig. 2 に示す. Fig. 2 に示すようにロボットの左右に一つずつ, 合計二つの球を配置する. 球の直径は $216[\mathrm{~mm}]$ で材質はエボ ナイトであり, 左右の球の中心間距離 $\ell$ は $400[\mathrm{~mm}]$ である. モー夕によって発生される角速度は減速機を通して駆動輪に伝 達され，これによって球が駆動される.駆動輪の直径は $60[\mathrm{~mm}]$ である．駆動輪と球との間の摩擦力を大きくするために, 駆動 輪の表面にはテニスラケットのグリップ用の滑べり止めのテー プを巻き,さらに駆動輪の反対方向にはウレタンの受動輪と可 調整バネを付ける. 駆動輪の取り付け角度は $\pi / 4[\mathrm{rad}]$ とする. また, ロボットの前後には転倒防止のために補助のキャスター 


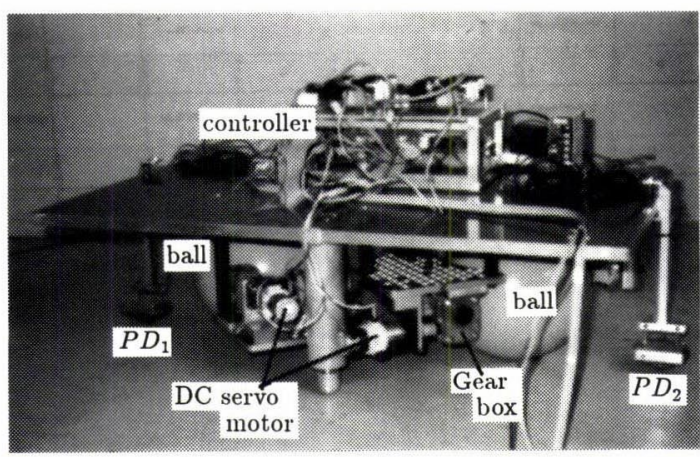

Fig.1 A prototype of the Cartesian nonholonomic robot
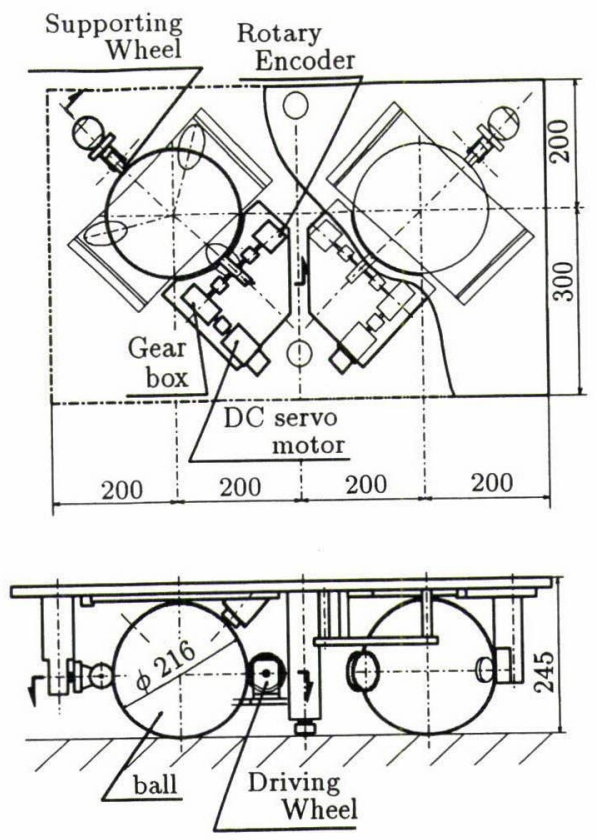

Fig. 2 Mechanism of the Cartesian nonholonomic robot

\section{を配置してある。}

\section{2 角速度伝達機構}

Fig. 3 に本ロボットの角速度伝達機構の構造を示す.ある時 刻 $t$ において, 駆動輪の回転方向と球の回転方向の角度差を $\psi(t)$, 駆動輪の角速度を $\omega(t)$, 球の角速度を $\Omega(t)$, 球の半径 を $R$, 駆動輪の半径を $r$, 球の回転方向に並行で駆動輪と球の 接点を通る円の半径を $R^{\prime}(t)$ とする.このとき, 駆動輪と球の 間で滑べりが生じないものとすれば, 駆動輪線速度 $w(t)$ は駆 動輪角速度 $\omega(t)$, あるいは球角速度 $\Omega(t)$ を用いて表せば次式 のようになる。

$$
\begin{aligned}
w(t) & =r \omega(t) \\
& =R^{\prime}(t) \Omega(t)=R \Omega(t) \cos \psi(t)
\end{aligned}
$$

ところで, 球の進行方向への速度を $W(t)$ とすれば,

$$
W(t)=R \Omega(t)
$$

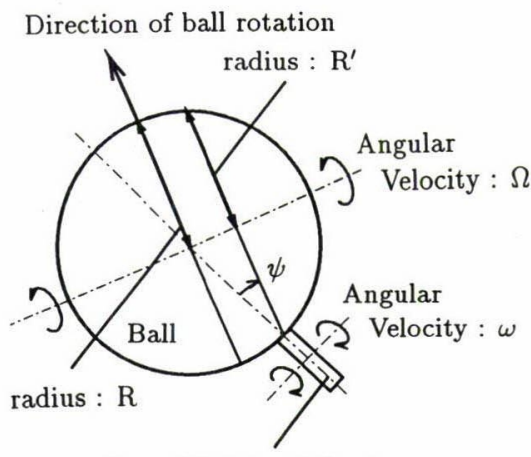

radius of Driving Wheel : $r$

Fig. 3 Directions of ball rotation and driving wheel

と表される。したがって, $W(t)$ を $w(t)$ を用いて表せば,

$$
W(t)=\frac{w(t)}{\cos \psi(t)}
$$

となり, $W(t)$ には進行方向によって決まる係数 $(1 / \cos \psi(t))$ が $w(t)$ にかかってくる，例えば，ロポットが直進するとき $(\psi(t)=\pi / 4[\mathrm{rad}])$ は

$$
W(t)=\frac{w(t)}{\cos (\pi / 4)}=\sqrt{2} w(t)
$$

で, $W(t)$ は $w(t)$ より $\sqrt{2}$ 倍だけ大きくなる. しかし, 文献 [1] で考えている $w_{1}$ あるいは $w_{2}$ はここで考えている駆動輪線速 度と $w(t)$ と一致しているので $W(t)$ を求める必要はない.

\section{3 運動学モデル}

慣性座標系 $O X Y$ に対する本ロボットの運動学モデルは左側 の駆動輪線速度を $w_{1}$, 右側を $w_{2}$ として記述すれば以下のよ うになる。

$$
\left\{\begin{array}{l}
\dot{x}=\sqrt{2}\left\{\left(w_{2}-w_{1}\right) \cos \phi-\left(w_{1}+w_{2}\right) \sin \phi\right\} / 2 \\
\dot{y}=\sqrt{2}\left\{\left(w_{2}-w_{1}\right) \sin \phi+\left(w_{1}+w_{2}\right) \cos \phi\right\} / 2 \\
\dot{\phi}=\sqrt{2}\left(w_{2}-w_{1}\right) / \ell
\end{array}\right.
$$

ここで, 2 球の中心間距離を $\ell, 2$ 球の中点をロボットの位置 $(x, y), 2$ 球の連結線と $O X$ 軸とのなす角度をロボットの姿勢 角 $\phi$ とする.

さらに, 簡単のために $u_{1}=\frac{\sqrt{2}}{2}\left(w_{2}-w_{1}\right), u_{2}=\frac{\sqrt{2}}{2}\left(w_{2}+w_{1}\right)$ とおくと, 式 (1) は

$$
\left\{\begin{array}{l}
\dot{x}=\cos \phi u_{1}-\sin \phi u_{2} \\
\dot{y}=\sin \phi u_{1}+\cos \phi u_{2} \\
\dot{\phi}=\frac{2}{\ell} u_{1}
\end{array}\right.
$$

と書ける。また, 次のような座標変換

$$
\left\{\begin{array}{l}
\xi_{1}=\phi \\
\xi_{2}=\frac{\ell}{2}-x \sin \phi+y \cos \phi \\
\xi_{3}=x \cos \phi+y \sin \phi
\end{array}\right.
$$

と入力変換

$$
\left\{\begin{array}{l}
v_{1}=\frac{2}{\ell} u_{1} \\
v_{2}=-\frac{2}{\ell}(x \cos \phi+y \sin \phi) u_{1}+u_{2}
\end{array}\right.
$$


によって，式（2）の方程式は Chained Form

$$
\left\{\begin{array}{l}
\dot{\xi}_{1}=v_{1} \\
\dot{\xi}_{2}=v_{2} \\
\dot{\xi}_{3}=\xi_{2} v_{1}
\end{array}\right.
$$

に変換される。

\section{3. 位置・姿勢センサ}

ロボットの位置・姿勢センサは内界センサと外界センサに大 別できる。

外界センサによる位置・姿勢計測方法の多くは三角測量に基 づいており，超音波を用いる方法 [5]などが研究されている。こ れは，室内に超音波の発信源を設置し，これに対する室内での ロボットの絶対位置と座標を求めるというものである．超音波 はターゲット以外からの反射波の影響を受けたり，気温によっ て音速が変化するために常に音速の補正が必要であるという問 題がある。

一方，車輪式移動ロボットで多く利用されている内界センサ は駆動輪の回転角度をロータリエンコーダにより測定し，位置・ 姿勢を求めている．しかし，駆動輪にはトルクがかかっている ため，滑りが生じる場合がある．そこで，キャスターを計測輪 として用い, FOG（光ファイバージャイロ）と組み合わせて位 置・姿勢を計測する研究がなされている [6].このセンサを用い て任意の曲線軌道を約 $1.7[\mathrm{~m}]$ 動かしたときの誤差が $X$ 方向で $2.3[\mathrm{~mm}], Y$ 方向で $3.5[\mathrm{~mm}]$ 程度という報告がなされている。 ここで用いられている FOG は高精度ながら，形状が大きく非 常に高価であるという欠点がある.

\section{1 センサの原理}

本研究では全方位への移動でも計測が可能で，しかも安価て 入手しやすいパーソナルコンピュータ用のポインティングデバ イス $P D$ （トラックボール，マウスなど）を二つ用いて位置・ 姿勢センサを開発した。

Fig. 4 に示すように $P D_{1}$ から中点, 中点から $P D_{2}$ の距離 を $L_{1}, L_{2}$, 慣性座標系 $O X Y$ からみた $P D_{1}$ の $X$ 座標を $x_{1}$ ， $Y$ 座標を $y_{1}$ とする。 また,$d t[\mathrm{~s}]$ での $P D_{1}$ の $X^{\prime}$ 軸方向の 移動距離を $d x_{1}, Y^{\prime}$ 軸方向の移動距離を $d y_{1}, P D_{2}$ の $Y^{\prime}$ 軸 方向の移動距離を $d y_{2}$ とする.

$d t[\mathrm{~s}]$ での姿勢の変化量は

$$
d \phi=\tan ^{-1}\left(\frac{d y_{2}-d y_{1}}{L_{1}+L_{2}}\right)
$$

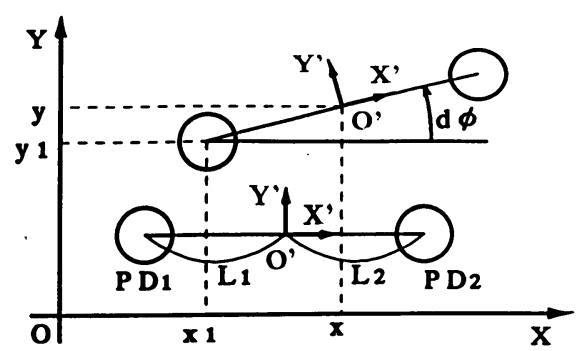

Fig. 4 Coordinate system of the sensor
と表すことができる．これより現在の姿勢 $\phi^{\langle n\rangle}$ は $d t[\mathrm{~s}]$ 前の 姿勢 $\phi^{\langle n-1\rangle}$ を用いて

$$
\phi^{\langle n\rangle}=\phi^{\langle n-1\rangle}+d \phi
$$

で求められる.

$P D_{1}$ の座標は

$$
\left\{\begin{array}{l}
x_{1}^{\langle n\rangle}=x_{1}^{\langle n-1\rangle}+d x_{1} \cos \phi^{\langle n\rangle}-d y_{1} \sin \phi^{\langle n\rangle} \\
y_{1}^{\langle n\rangle}=y_{1}^{\langle n-1\rangle}+d x_{1} \sin \phi^{\langle n\rangle}+d y_{1} \cos \phi^{\langle n\rangle}
\end{array}\right.
$$

であるから，ロボットの位置は

$$
\left\{\begin{array}{l}
x^{\langle n\rangle}=x_{1}^{\langle n\rangle}+L_{1} \cos \phi^{\langle n\rangle} \\
y^{\langle n\rangle}=y_{1}^{\langle n\rangle}+L_{1} \sin \phi^{\langle n\rangle}
\end{array}\right.
$$

で求めることができる.

\section{2 性能評価}

Fig.5 に示すようにロボットにセンサを実装し, 性能評価を 行った．ロボットを前方に約 $1[\mathrm{~m}]$ 移動させたときの軌跡（セ ンサ出力值）とロボット停止時における位置（実測值とセンサ 出力值）を Fig. 6 に示す. Table 1 にロボット停止時における 位置・姿勢の実測値，センサ出力値および誤差を示す．式（9） から分かるように, 姿勢 $\phi^{\langle n\rangle}$ の誤差が $x$ 方向および $y$ 方向の
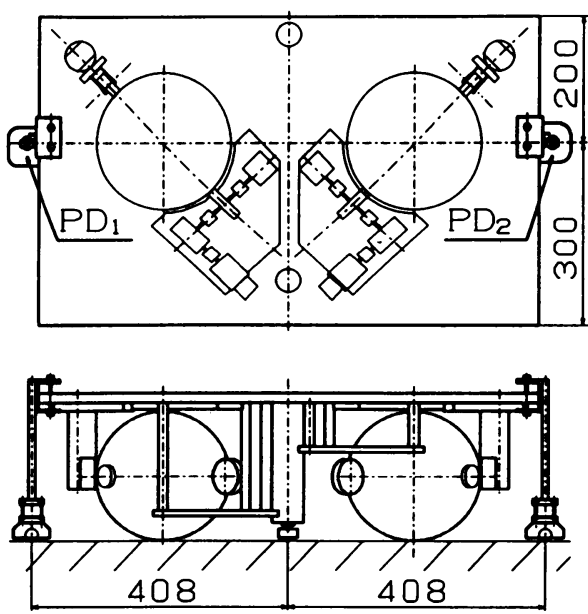

Fig. 5 Illustration of the robot with the sensor

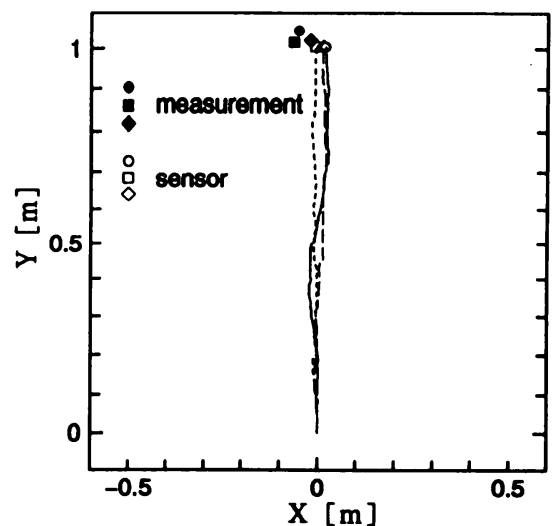

Fig. 6 Error evaluation of the sensor system 
Table 1 Error evaluation of the sensor system

\begin{tabular}{c|c|c||c|c|c||c|c|c}
\hline \multicolumn{3}{c||}{ measurement } & \multicolumn{3}{c||}{ sensor } & \multicolumn{3}{c}{ error } \\
\hline$x[\mathrm{~m}]$ & $y[\mathrm{~m}]$ & $\phi[\mathrm{rad}]$ & $x[\mathrm{~m}]$ & $y[\mathrm{~m}]$ & $\phi[\mathrm{rad}]$ & $x[\mathrm{~m}]$ & $y[\mathrm{~m}]$ & $\phi[\mathrm{rad}]$ \\
\hline \hline-0.051 & 1.050 & 0.097 & 0.019 & 1.005 & 0.001 & 0.070 & 0.045 & 0.096 \\
\hline-0.063 & 1.019 & 0.002 & -0.009 & 1.005 & 0.006 & 0.054 & 0.014 & 0.004 \\
\hline-0.022 & 1.021 & 0.002 & 0.014 & 1.006 & -0.015 & 0.036 & 0.015 & 0.017 \\
\hline
\end{tabular}

誤差の原因となる。また， $P D$ 内部で使用されている球と床 面あるいはロータリエンコーダ検出部での滑べりの発生, セン サの取り付け位置の誤差, 演算の丸め誤差などが本センサの誤 差の要因となる。さらに，ゴミ，ホコリなどが付着し，移動距 離が延びるにつれ精度が悪化することが考えられる。

\section{4. ロボットの制御}

本章では，前章で開発した位置・姿勢センサを用いて，ロボッ トの位置決めフィードバック制御について考える. 運動学モデ ルの妥当性と制御則の有効性および限界を検証するために, 計 算機シミュレーションと制御実験結果を比較しながら説明する.

\section{1 原点への安定化制御}

Chained Form 式 (5) が原点に収束するように制御入力 $v_{1}, v_{2}$ を決めれば, 式（3）の逆変換によってもともとのシステム式 (2) の入力が決まり, 座標 $(x, y, \phi)$ は $q^{*}=(0,-\ell / 2,0)^{T}$ に収 束する. $q=(x, y, \phi)^{T}$ の代わりに $q+q^{*}$ とすれば, $q$ は原 点に収束する。

文献 [1]で提案した制御則は，まずChained Form の状態を 有限時間内で多様体

$$
M=\left\{\xi \mid \xi_{2}=0, \xi_{3}=0, \xi_{1}=\text { 任意 }\right\}
$$

に到達させ,それから状態 $\xi_{1}$ を原点に収束させる. 制御入力 は次のように与える.

$$
\begin{aligned}
& \left\{\begin{array}{l}
v_{1}=c: \text { Const., } \xi \notin M \\
v_{2}=-\frac{v_{2 \max }}{c} \operatorname{sign}\left(\xi_{3}+c \dot{\xi}_{2}\left|\dot{\xi}_{2}\right| /\left(2 V_{2 \max }\right)\right)
\end{array}\right. \\
& \left\{\begin{array}{l}
v_{1}=-k \operatorname{sign}\left(\xi_{1}\right)-\alpha \xi_{1}, \quad \xi \in M \\
v_{2}=0
\end{array}\right.
\end{aligned}
$$

以下, この制御則を制御則 1 とする. 明らかに, 制御入力 $v_{2}$ のスイッチング周波数が無限大であれば, 状態は最終的に $M$ に入り， $\xi_{2}=\xi_{3}=0$ となる. しかし, ディジ夕ル計算機で制 御入力を実現するとき，スイッチング周波数はサンプリング周 波数 (有限) となるので, 多様体 $M$ の付近で制御入力のチャ タリングが生じやすい，これを克服するために，実験およびシ ミュレーションでは小さい正実数 $\epsilon$ を選んで, $M$ を

$$
M=\left\{\xi|| \xi_{2}|\leq \epsilon,| \xi_{3} \mid \leq \epsilon, \xi_{1}=\text { 任意 }\right\}
$$

と置き換えた。サンプリング周波数が高ければ， $\epsilon$ は小さく取 れる。

文献 [7] で Sørdalen は Chained Form に対して解析的でな い周期時変状態フィードバック制御則を構成し，閉ループ系の 指数安定性を証明している。以下, この制御則を制御則 2 とし 本ロボットの制御に適用する。

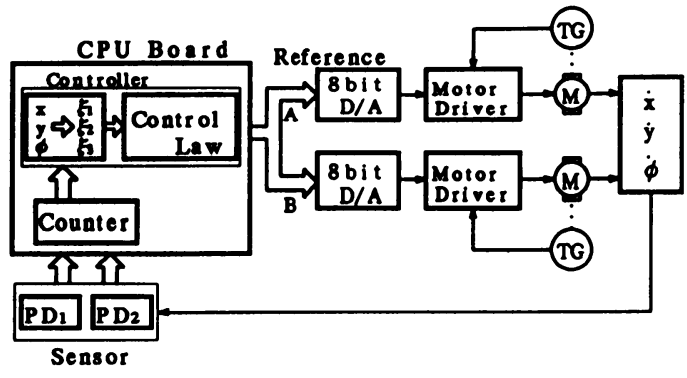

Fig. 7 Control system

\section{2 任意の位置・姿勢への安定化制御}

変数 $q_{e}=T\left(q_{r}\right)\left(q-q_{r}\right)$ を定義し, $q$ を $q_{e}$ で置き換え, 制 御則を適用すれば, 任意の目標値 $q_{r}=\left(x_{r}, y_{r}, \phi_{r}\right)^{T}$ へ安定化 することができる．ここで，変換行列 $T\left(q_{r}\right)$ は

$$
T\left(q_{r}\right)=\left[\begin{array}{ccc}
\cos \phi_{r} & \sin \phi_{r} & 0 \\
-\sin \phi_{r} & \cos \phi_{r} & 0 \\
0 & 0 & 1
\end{array}\right]
$$

である $[7]$.

\section{3 制御実験}

Fig. 7 に本ロボットの制御システム構成を示す. 制御システ ムはコントローラとなる V25 CPU ボード, ディジタル信号を 電圧に変換する 8 [bit] D/A コンバータ, 電力を増幅しモー夕 を駆動するモータドライバ，位置・姿勢センサからなる．

本論文ではシミュレーションおよび実験で次のようなパラ メータを設定する。

制御則 1: $c=0.045, V_{2 \max }=0.004, \alpha=0.1, k=0$

$$
M_{\epsilon}=\left\{\xi|\quad| \xi_{2}|\leq 0.05,| \xi_{3} \mid \leq 0.05, \xi_{1}=\text { 任意 }\right\}
$$

制御則 2: $\lambda=0.5, K=0.3, \kappa=0.5, \quad T=8 \pi$

なお, サンプリング周期は制御則 1 では $0.1[\mathrm{~s}]$, 制御則 2 では $0.15[\mathrm{~s}]$ とした.

目標値を $q_{r}=(0.3,0,0)^{T}$ すなわち, $X$ 軸方向に $0.3[\mathrm{~m}]$ の 移動を行わせるとして, 制御則 1 を適用してシミュレーション と制御実験を行った。このときのロボットの軌跡をそれぞれ Fig. 8 と Fig.9 に示す. Fig. 8, Fig. 9 から分かるようにロボッ トは始め前進して行き, あるところで運動の方向の切り返しを 行って目標に近づいていく動作が見られる．本ロボットは自動 車と同様に真横に移動することができない.したがって，自動 車の「車庫入れ」で見られるようなこのような動作は妥当であ ると思われる。

次に, $Y$ 軸方向に $0.3[\mathrm{~m}]$ の移動を考え, 目標値を $q_{r}=$ $(0,0.3,0)^{T}$ としたときの制御則 1 によるシミュレーションと 制御実験の結果をそれぞれ，Fig.10 と Fig.11に示す．目標が 


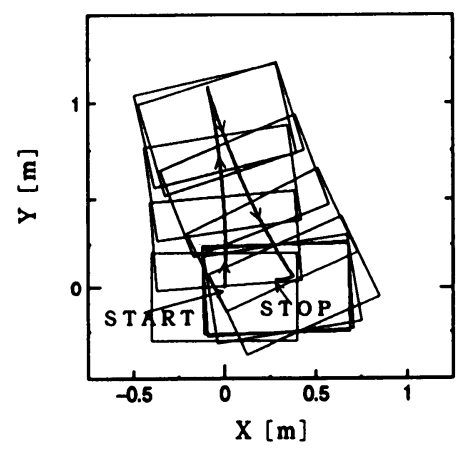

Fig. 8 Simulation result using Control law 1 with $q_{r}=(0.3,0,0)^{T}$

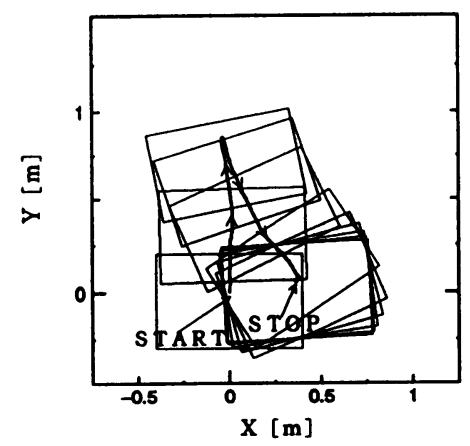

Fig.9 Experimental result using Control law 1 with $q_{r}=(0.3,0,0)^{T}$

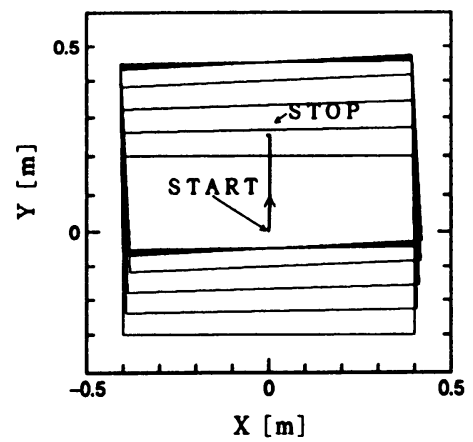

Fig. 10 Simulation result using Control law 1 with $q_{r}=(0,0.3,0)^{T}$

$Y$ 軸上で，しかも姿勢が初期值と同じ場合は左右の入力を等し くすることで本ロボットは目標值に到達することができる．し かし，Fig.10，Fig.11で見られるように本制御則ではロボット は多様体に収束してから姿勢の修正を行い, 目標值に到達して いる.

また, ロボットの姿勢変更制御を行うために, 目標值を $q_{r}=(0,0, \pi / 4)^{T}$ とした. 制御則 1 を適用してシミュレーショ ンと制御実験を行った結果を Fig. 12, Fig. 13 に, 制御則 2 を 適用して制御実験を行った結果を Fig. 14 に示す. 本ロボット はその場旋回（回転半径が 0) ができないため, 姿勢変更のみ を行おうとする場合は，いったん，初期位置から遠ざかり，姿

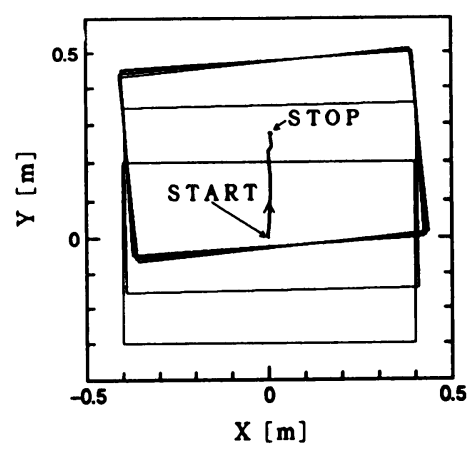

Fig. 11 Experimental result using Control law 1 with $q_{r}=(0,0.3,0)^{T}$

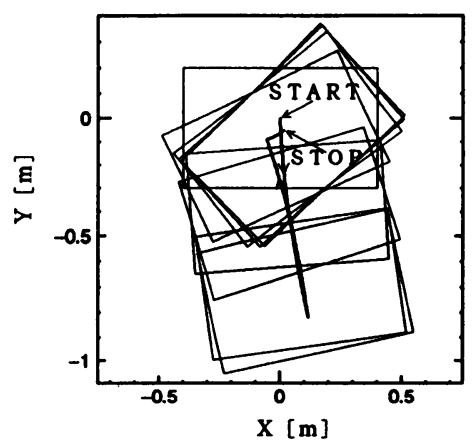

Fig. 12 Simulation result using Control law 1 with $q_{r}=(0,0, \pi / 4)^{T}$

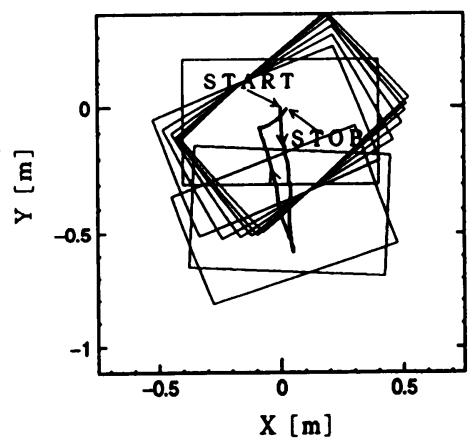

Fig. 13 Experimental result using Control law 1 with $q_{r}=(0,0, \pi / 4)^{T}$

\section{勢変更を行わなければならない.}

こうした動作を行う場合，制御則 1では，はじめに後退して いき，ある点で前進運動に切替を行う．また，多様体に収束し た時点で入力の切替を行い, 目標の位置・姿勢に安定化させて いる.

なお，制御で用いたサンプリング周波数は比較的低いので， 先に述べたよう $\epsilon=0.05$ と取り，多様体を $M_{\epsilon}=\left\{\xi|| \xi_{2} \mid \leq\right.$ $0.05,\left|\xi_{3}\right| \leq 0.05, \xi_{1}=$ 任意 $\}$ と設定した。 そのため, 位置決 めに定常誤差が見られたと思われる。

制御則 2 では原点を出発点とし楕円状の軌跡を描き, 再び原 点に戻りながら姿勢の変更を行っている. 制御則 1 に比へて滑 


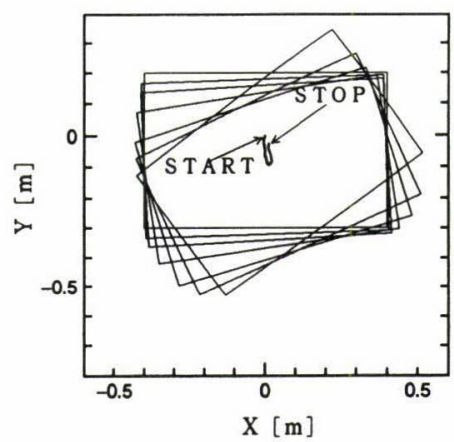

Fig.14 Experimental result using Control law 2 with $q_{r}=(0,0, \pi / 4)^{T}$

らかな軌跡を描いていることが分かる。

制御則 1 について, シミュレーションと実験で類似した軌跡 が得られていることが分かる。これは, ロボットの運動学モデ ルが正確に得られていることを示唆している．実験での軌跡の 誤差は, 理想モデルで駆動輪一球が点接触しているところを駆 動輪からみた系全体の慣性に打ち勝つ駆動力を球に与えるため 面接触にしたことによるモデル誤差, ロボットの加工および組 み立て精度, 入力（モー夕の速度）の誤差, 床面の凹凸の影響, 駆動輪一球の滑べりの発生, センサの誤差などが原因している ものと思われる。

特に面接触にしたことによるモデル誤差は, 積載重量が大き くなるほど顕著に現れることが予想される。点接触で大きな駆 動力を伝えることが可能な機構の設計を今後の課題としたい.

\section{5. 結論}

二つの球と二つのアクチュエータを使った非ホロノミック移 動ロボットを製作した。また，マウスを二つ用いた位置・姿勢 センサを開発した。精度に問題はあるがコストが安く, 全方位 への計測が可能であるというメリットがある.

本ロボットに対し, 制御則を適用し, シミュレーションによっ

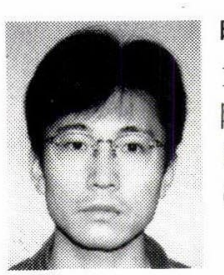

町田健一 (Kenichi Machida)

1971 年 6 月 3 日生. 1996 年長岡技術科学大学大学 院工学研究科修士課程修了. 同年 4 月よりダイダ ン株式会社に勤務. 非ホロノミックロボットの研究 に興味を持つ。

(日本ロボット学会正会員)

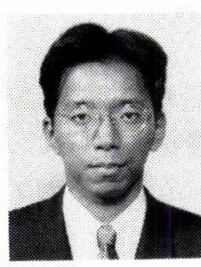

船木陸議 (Michitaka Funaki)

1967 年 9 月 12 日生. 1993 年大阪大学大学院基礎 工学研究科博士課程前期修了. 同年日本電気株式 会社入社, 1994 年長岡技術科学大学助手 (機械系) となり現在に至る。宇宙ロボット, 非ホロノミック システムの研究に興味を持つ。計測自動制御学会 の会員.

(日本ロボット学会正会員)
てロボットの移動の軌跡の確認をした.その結果, 任意の目標 值に安定化できることが確認された。

開発したセンサの情報を用いてロボットの制御実験を行った. 制御則 1 , 制御則 2 ともに本ロボットを任意の位置・姿勢へ安 定化できることが確認できた。しかし, 収束を判定する多様体 によって誤差が残ることが分かった，目標へのより高精度な安 定化には

・D/A コンバータの分解能を高める

・多様体をより 0 に近づける

・高速な CPU を使い, サンプリング周波数を上げる などの方法が考えられる。

\section{謝辞}

実験装置を製作していただいた（株）ダブル技研の和田博社 長, 御器谷科学技術財団, 機械工業振興財団に感謝の意を表し ます。

\section{参 考 文 献}

[1 ] 羅, 船木：“直交座標型非ホロノミックロポットの設計と制御”, 日本 ロボット学会誌, vol.13, no.7, pp.1038-1043, 1995.

[2] 松本直樹, 竹田滋, 飯田慎二, 伊東正篤：“三つの球を使った全方位移 動機構の運動と制御”, 日本機械学会論文集（C 編）, vol.60, no.576, pp.226-273, 1994.

[3] 飯田慎二, 竹田滋, 松本直樹, 伊東正篤：“球を使った全方位移動機 構およびその制御”、第 3 回ロボットシンポジウム予稿集, pp.79-83, 1993.

[4] 西川晃平, マークウエスト, 浅田春比古：“ホロノミック特性を有す る全方向移動ロボットと移動ロボットの高精度誘導方式の開発”, 日 本ロボット学会誌, vol.13, no.2, pp.249-256, 1995.

[5] 新井健生, 中野栄二: “移動車搭載形位置方向計測装置の開発と性能 評価”, 計測自動制御学会論文集, vol.18, no.10, pp.1013-1020, 1982.

[6] 阿部国寛, 三枝靖典, ラモスフタペア, 高島俊：“自律移動ロボット のキャスターを用いた位置・方位センシングシステム”, 日本機械学会 ロボティクス・メカトロニクス講演会 '95 予稿集, pp.434-437, 1996.

[ 7 ] O.J. Sørdalen: "Feedback control of nonholonomic mobile robots," Ph.D. Thesis, The norwegian Institute of Tech., 1993.

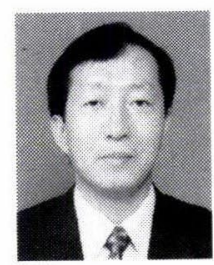

羅 正華 (Zheng-Hua Luo)

1962 年 2 月 14 日生. 1990 年大阪大学大学院基礎 工学研究科博士課程修了. 同年より同大学基礎工 学部制御工学科 (現システム工学科) 助手. 1994 年より長岡技術科学大学助教授 (機械系) となり 現在に至る. 分布定数系の理論とその応用, ロボッ ト, 線型力学系, および非ホロノミックシステムの 研究に興味を持つ. 工学博士. IEEE, 計測自動制御学会, システム 制御情報学会などの会員.
(日本ロボット学会正会員) 